\title{
Evaluation Strategy to Support the Introduction the New Cuban Conjugated Pneumococcal Vaccine in the National Health System
}

Nivaldo Linares-Pérez ${ }^{1^{*}}$, María E. Toledo-Romaní ${ }^{2}$, Daryelis Santana Mederos ${ }^{1}$, Yury Valdés-Balbín ${ }^{1}$, Dagmar García-Rivera ${ }^{1}$, Vicente Vérez-Bencomo ${ }^{1}$

${ }^{1}$ Vaccine Institute, Havana, Cuba

${ }^{2}$ Tropical Medicine Institute "Pedro Kouri" (IPK), Havana, Cuba

"Corresponding author: Nivaldo Linares-Pérez, Clinical Research and Impact Evaluation, Finlay Vaccine Institute, Av. 21 \#19810 e/198 y200, Atabey, Playa, P.O. Box 16042, Havana, Cuba, Tel: +53 72715032; E-mail: nlinares@finlay.edu.cu

Received date: October 18, 2017; Accepted date: February 02, 2018; Published date: February 09, 2018

Copyright: $@ 2018$ Linares-Pérez N, et al. This is an open-access article distributed under the terms of the Creative Commons Attribution License, which permits unrestricted use, distribution, and reproduction in any medium, provided the original author and source are credited.

\begin{abstract}
Objective: To present the evaluation framework supporting the clinical, epidemiological and impact studies to introduce the new Cuban conjugated pneumococcal vaccine in the national vaccination program.

Methods: The design of the evaluation strategy of the new vaccine in the Cuban included: the revision of the scientific evidence available in literature, the definition of the evaluation objectives, the application of conceptual and methodological evaluation frame, the performance of the process to generate the new scientific evidences about the new vaccine. The regulatory frame for the evaluation and introduction of new PCVs were taken into consideration during the whole process.

Results: The background of licensed pneumococcal vaccine with similarly based studies was synthetized. The evaluation strategy of the Cuban vaccine was presented in terms of objectives, key processes, and main components (context evaluation, generation of evidence for making-decisions, introduction of the new vaccine and impact evaluation). The procedures to collect information and analysis of the new evidence generated on PCV7-TT are defined (characterize the study problem, the functioning of the new vaccine, and cost-effectiveness and impact). The evaluation strategy is operationalized in the Cuban context, where preschool children and infants are defined as target population. The contributions, strengths and weaknesses in the evaluation design and in the generation of evidences are discussed.
\end{abstract}

Conclusions: The rigorous scientific evidences generated by the implementation evaluation strategies, applied to the new Cuban conjugated pneumococcal vaccine will allow the decision-making for its introduction to national health system in Cuba.

Keywords Pneumococcal conjugated vaccines; Vaccine effectiveness; Impact evaluation; Evidence; Evaluation; Cuba

\section{Introduction}

In Cuba, acute respiratory diseases are among the main causes of hospitalization and death in childhood. The pediatric consensus for the diagnosis and treatment of pneumonia acquired by children refers that children under five years old show the highest rate of mortality of probable pneumococcal etiology [1,2].

Information on the isolation of different serotypes of pneumococcus in hospitalized cases confirms the highest burden of the disease among children under five years, associated to meningitis (63\%) and pneumonias (37\%) [3,4]. Before 2014, there are not surveillance system established to document the burden of the pneumococcal disease in the whole country, which explains why the highest number of isolations came from cerebrospinal fluid CRF for etiologic diagnosis of bacterial meningitis $[4,5]$.

Available pneumococcal vaccines (PCVs) are safe and immunogenic, however the vaccination coverage remains low in many countries [6], due to its high prices, which are above $\$ 100$ dollars per dose in the commercial network and from $\$ 14$ to $\$ 16$ if supplied to public health programs [7]. The WHO has recognized the need of designing new candidates that improve coverage in all regions [8]. For this purpose registry standards have been fixed based on: 1) immunological criteria of non-inferiority (percentage of children reaching antibody levels of $0.35 \mu \mathrm{g} / \mathrm{mL}$ after a month of the third dose of the primary series by ELISA method), 2) functionalityopsonophagocytic activity and evidence of "priming effect" or memory, 3) safety demonstration and 4) confirmation of use with vaccines administered at the same time [6].

So far, the pneumococcal vaccination has not been introduced in the Cuban immunization program, due mainly to high costs of available vaccines in the international market. However, the government, the health system and the biotechnological industry of the country have given priority to the development of a conjugated heptavalent pneumococcal vaccine candidate since 2006 in order to reduce the burden of pneumococcal disease.

The new Cuban conjugated vaccine contains the seven serotypes more prevalent worldwide and represented in more than $60 \%$ of isolated serotypes [9,10]. Recently in April 2017 a new technical document of the Pneumococcal Global Serotype Project (GSP) "Pneumococcal Conjugate Vaccine (PCV) Product Assessment April 2017 [11] confirm that the seven serotypes included in PCV7-TT 
Citation: Linares-Pérez N, Toledo-Romaní ME, Mederos DS, Valdés-Balbín Y, García-Rivera D, et al. (2018) Evaluation Strategy to Support the Introduction the New Cuban Conjugated Pneumococcal Vaccine in the National Health System . J Vaccines Vaccin 9: 385. doi: $10.4172 / 2157-7560.1000385$

Page 2 of 8

representing $66.4 \%$ of the total causing IPD in LAC. Also this document highlight that only a small subset of these serotypes are responsible for the vast majority of disease and deaths, they were targeted for inclusion in PCVs to represent those found across all epidemiologic settings.

The eight years for develop the Cuban vaccine have been very complex from the scientific, chemical, analytical and technological viewpoint since it is a multivalent vaccine based on the conjugation of seven pneumococcal capsular polysaccharide antigens. The composition of the vaccine candidate includes $2 \mu \mathrm{g}$ of serotypes 1,5 , $14,18 \mathrm{C}, 19 \mathrm{~F}, 23 \mathrm{~F}$ and $4 \mu \mathrm{g}$ of serotype $6 \mathrm{~B}$, all of them conjugated in the carrier protein Tetanus toxoid and it is adjuvated to aluminum phosphate to ensure adequate doses of each formulated component.

PCV7-TT was developed bearing in mind the following criteria: a) to include seven serotypes, learning from Prevnar-7 that the impact of PCV could be high if the selected serotypes matched the current epidemiology well; b) to use tetanus toxoid conjugates to increase the immunogenicity induced against the serogroups 19 and 6 through 19F and $6 \mathrm{~B}$ conjugates; and $\mathrm{c}$ ) to reduce the time of pharmaceutical development by reducing the complexity of the vaccine and making it available the earliest possible.

To build the body of scientific evidences based on the clinical research and impact evaluation for the introduction of pneumococcal vaccination, is also very complex. This statement is supported by : 1) the need of demonstrating the direct and indirect effect, as well as the global impact in target population (under 5-years-old), combining both experimental and observational studies, 2) the limitations from the surveillance systems and the health statistics to provide baseline information and to screen changes in the burden of invasive and noninvasive pneumococcal disease, 3 ) the low isolation rates mainly in samples from respiratory infections, and 4) the technological difficulties to support integrated clinical, epidemiological and microbiological surveillance systems.

The scientific problem was guided by two main questions: 1) what is the rationale for introducing the pneumococcal vaccination in infant population in Cuba? and 2) How to build an evaluation frame to support the scientific evidence for decision making on the vaccine introduction, use and commercialization?. The objective of this paper is to present the strategic framework supporting the clinical, epidemiological and impact evaluation to support the introduction the new Cuban conjugated pneumococcal vaccine in the national vaccination program.

\section{Methods}

The building process of the evaluation strategy for the new Cuban vaccine has followed a sequential steps including: the revision of the scientific evidence available in literature, the definition of the evaluation objectives, the application of conceptual and methodological evaluation frame, the performance of the process to generate the new scientific evidences about the new vaccine, and the operationalization in the Cuban context.

The conceptual and methodologic frame was based by the consensus of experts involved in the manufacturing and evaluation of vaccines and researchers from institutions of the national health system. Key processes and main components of the evaluation strategy were defined to ensure the internal validity of the information and the applicability for other contexts and products (vaccines) under research.
The regulatory frame for the evaluation and introduction of new PCVs were taken into consideration during the whole process, including WHO position documents [6] and the Cuban regulations established by the Center for State Control of Medicament, Equipment and Medical Devices (CECMED, acronym in Spanish) from the Ministry of Public Health in Cuba [12].

The syntheses of the available evidence were performed from metanalysis and the systematic reviews published about PCVs Besides, guides, regulations, and effectiveness measures in evaluations of similar already registered vaccines were also reviewed.

The evaluation strategy for the generation of new evidence on PCV7-TT combines experimental, quasi-experimental and observational approaches. Vaccine clinical evaluation phases and the conceptual frame proposed by the Medical Research Council for complex interventions [13] were used as reference. The former uses a scaled approach (by step or phases) as part of a large list of interactive activities to define the research process.

A systematic monitoring of indicators was established to ensure quality of the generation process of scientific evidence: 1) quality of primary information (internal validity), having considered international guides that explore the rigor of studies, data reliability and biases [14];2) applicability of results to target population from evidences provided by clinical and community trials; and 3) cost and cost-effectiveness studies as suggested by the ProVac initiative [15].

The levels and gradation of evidences take into account the suggestions of the proposal of the workgroup GRADE, which uses the classification in levels from A to E, to formulate recommendations for introduction and use of new products or technologies [16].

The design, writing and the application of the evaluation strategies was financed by the "Finlay Vaccine Institute", and the conduction and implementation of the studies will be carried out by researchers from institutions of the National Health System.

\section{Results}

\section{Objectives definition}

The objectives of the evaluation were defined as follow: 1) to characterize the pneumococcal disease, the circulation of serotypes and the nasopharyngeal colonization in children under 5 years, 2) identify risk factors associated to prevalence of nasopharyngeal colonization and the occurrence of pneumococcal disease, 3) to estimate costs for health services and family expense associated to pneumococcal disease care in children, 4) to evaluate safety, immune response and protective efficacy of the Cuban vaccine candidate PCV7TT, 5) to estimate the effectiveness of the program in both controlled and real life scenarios and to model the population effect, and 6) to evaluate the impact on health due to the introduction of the new Cuban pneumococcal vaccine.

\section{The evaluation strategy}

Key processes and main components of the evaluation strategy are summarized in figure 1 . 
Citation: Linares-Pérez N, Toledo-Romaní ME, Mederos DS, Valdés-Balbín Y, García-Rivera D, et al. (2018) Evaluation Strategy to Support the Introduction the New Cuban Conjugated Pneumococcal Vaccine in the National Health System . J Vaccines Vaccin 9: 385. doi: $10.4172 / 2157-7560.1000385$

Page 3 of 8

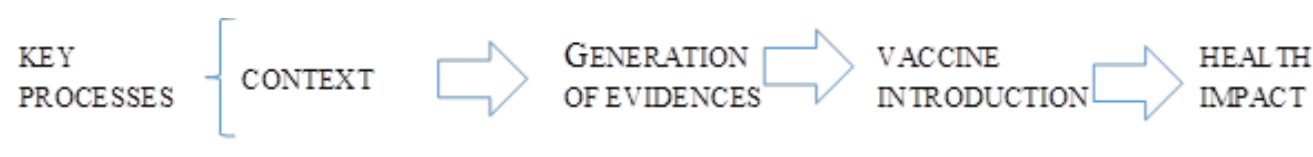

\section{(I) CONTEXT ANALY SIS}

Political will, national health system and Cuban biotechnological industry

Scientific evidences on the effectiveness and impact of PCV s and WHO recommendations.

The Cuban vaccinne candidate PCV7-TT developed in Cuba.

National Vaccination programm e, laboratories and clinical sites for research

(II) EVIDENCE SEARCH AND GENERATION

\begin{tabular}{l|l|l|}
$\begin{array}{l}\text { A. Revision and synthesis } \\
\text { of available scientific } \\
\text { evidence }\end{array}$ & $\begin{array}{l}\text { B. Generation of new } \\
\text { Scientific evidence }\end{array}$ & $\begin{array}{l}\text { C. Analysis and valuation } \\
\text { of scientific evidence }\end{array}$ \\
\end{tabular}

(III) VACCINE INTRODUCTION

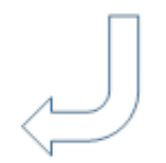

\section{(IV) ME ASUREMENT OF HEAL TH IMPACT}

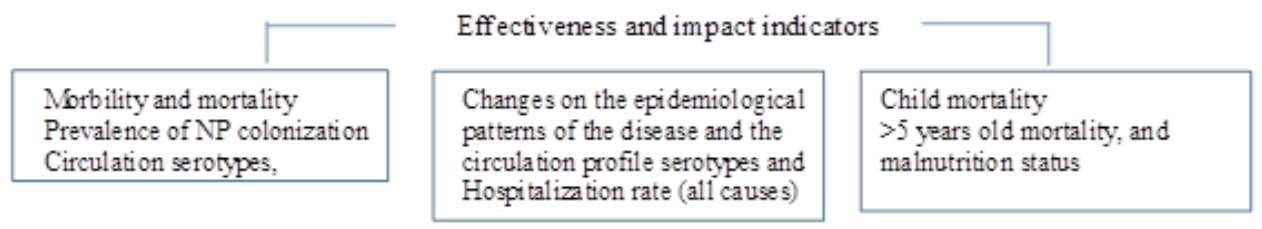

\section{Source : Expert consensus}

Figure 1: Processes and components of the model evaluation for the introduction of the new vaccine.

\section{Key processes}

It was defined as follow: I) context evaluation, referred to the political and technical will for development, evaluation and vaccine introduction; II) available evidence review and generation of new one to make decisions on its introduction and commercialization. It includes definition and understanding the health problem, synthesis of the scientific evidence available in literature, research design, implementation and evaluation of generated evidence; III) introduction of the vaccine in the National Vaccination Program; and IV) measurement of impact on population health related to the use of PCV7-TT (Figure 1).

\section{Main Components}

\section{(I) Context analysis}

Several aspects from Cuban reality according to political, health services organization and research capacities were took into account: 1) the political will of the government, of the health system and of the biotechnological industry for introducing new vaccines and making them available to other countries and populations with limitations to access the existing commercial vaccines; 2 ) the capacity demonstrated by Cuban scientists to design and develop successfully complex vaccines, which has made possible to develop a pneumococcal vaccine candidate according to standards required for conjugated vaccines; 3 ) a health system with universal coverage including all care levels, diagnosis and reference services, public health programs and study sites where the agenda of clinical research and evaluation is implemented.

Review of available evidence and generation of new research findings for making-decisions:

\section{(II) Evidence Search and Generation}

\section{A) Review and synthesis of available scientific evidence}

Some available evidences on safety, immunogenicity, protective efficacy and effectiveness of PCVs have been summarized as follows:

Vaccine safety in children and infants [17]. Evidence of 13 clinical assays conducted in North America, Europe and Asia was grouped in a metanalysis including 9 countries. It demonstrated that the rate of local adverse events of each dose was similar between PCV13 and PCV7. The frequency of fever was also similar among groups, being fever $<39^{\circ}$ predominant. For PCV13, the incidence of fever from $39^{\circ}$ to $40^{\circ}$ was 
Citation: Linares-Pérez N, Toledo-Romaní ME, Mederos DS, Valdés-Balbín Y, García-Rivera D, et al. (2018) Evaluation Strategy to Support the Introduction the New Cuban Conjugated Pneumococcal Vaccine in the National Health System . J Vaccines Vaccin 9: 385. doi: $10.4172 / 2157-7560.1000385$

Page 4 of 8

$2.8 \%$ after each dose in infants while $5.0 \%$ in older children. It can be concluded that PCV13 has a favorable safety profile, similar to that of PCV7.

Immunogenicity related to the use of different immunization schemes [18]. Information from randomized clinical trials, nonrandomized studies, surveillance and observational studies was included. The IgG GMCs after the primary series was higher with schemes of 3 doses than with 2 doses for all serotypes, except serotype 1. However, these concentrations were similar after administering a booster dose in any of the two schemes. The immunological response was higher when the third dose was administered after 23 months $(2+1)$, compared to vaccination in infants less than 6 months of age $(3+0)$.

Effect of different vaccination schedules in nasopharyngeal colonization [19]. From the information of 16 controlled studies and 11 observational studies with after/before designs, a decrease in the nasopharyngeal carrier status when using $2 p+0,2 p+1,3 p+0$ and $3 p+1$ was demonstrated. However, comparisons between schemes showed that the use of primary schemes of 3 doses can achieve a higher reduction than schemes of 2 primary doses $(2+1$ and $2+0)$.

Efficacy of different immunization schedules in the reduction of invasive disease [20]. The optimum schedule to ensure maximum protection against the invasive disease is not known. Studies published from 1994 and 2010 were reviewed and summarized to evaluate the benefits of different schemes, in addition studies from 2011 from the region and Europe were used to supplement them. Data series of two and three doses with and without booster dose (" $2 p+0$," " $2 p+1$," " $3 p+0$ " and " $3 p+1)$ were evaluated. Efficacy demonstrated in clinical assays ranges from $65 \%$ to $71 \%$ with schemes $3 p+0$ and from $83 \%$ to $94 \%$ with $3 p+1$. Surveillance studies and case series have documented a reduction of invasive disease up to $100 \%$ with schemes $2 p+1$ (6 studies) and $3+1$ ( 17 studies) and up to $90 \%$ with $3+0$ ( 2 studies). These reductions were early observed, a year after the introduction of PCVs.

Differential impact of vaccine coadministration, geographic regions, the vaccine and other covariables associated to immunogenicity of PCVs [21]. Different information sources, including reports, lectures, summaries and unpublished data from studies conducted between 1994 and 2011 were combined. It was concluded that the immune response to pneumococcal vaccines is associated to the geographic region and the vaccine used, but the association and magnitude varies for different serotypes. Besides, it is suggested that these factors should be considered when immunogenicity comparisons are established among groups and when the better scheme in different contexts is being chosen.

Cots-effectiveness systematic review qbout Pneumococcal Vaccination in Children in Low- and Middle-Income Countries [22]. It 's demonstrated that an infant PCV programme was a cost-effective intervention in most LMICs (in 20 of 22 studies included). The results were sensitive to vaccine efficacy, price, burden of disease and sponsorship. The authors suggest that decision makers should consider EE findings and affordability before adoption of PCVs.

B) Generation of the new scientific evidence

Steps and procedures for the generation of evidences on PCV7-TT are summarized in Figure 2.

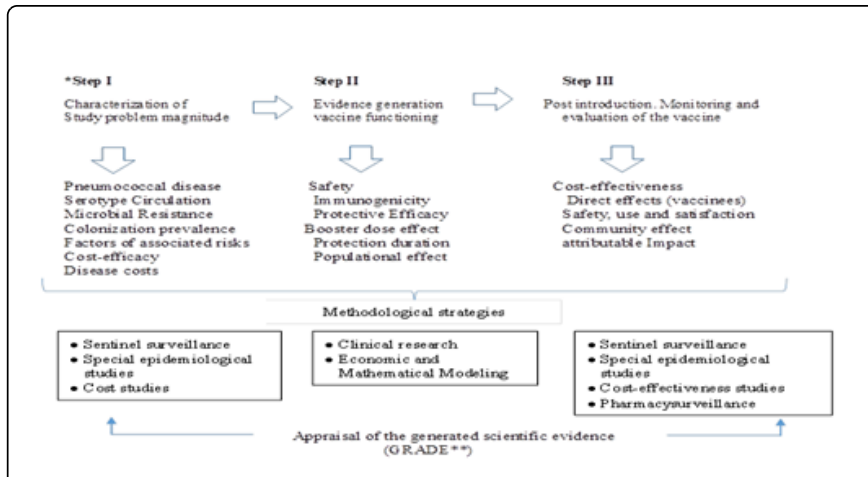

Figure 2: Steps and strategies for the generation of the scientific evidence on the new vaccine (PCV7-TT).

The methodological procedures to collect information in Step I (to characterize the study problem) include:

Population-based sentinel surveillance: Case studies of diseases (syndromes) associated to pneumococcal infection in hospitals and primary health care combining clinical, epidemiological and microbiological aspects.

Special epidemiological studies: To estimate the magnitude of the problem in terms of burden of disease, nasopharyngeal colonization and risk factors associated.

Economic evaluation: focused on the estimation of costs of illness (using public health perspective) and out pocket expenses of the family.

Research methodologies to provide evidences on the functioning of the new vaccine regarding safety, immunogenicity, efficacy, costs and cost-efficacy (Step II) included:

Clinical research (based on controlled clinical trial). From Fase I-IV (RPCEC00000255). A cluster community trial is conducting in 2017 to measure the population impact and the herd effect (previous to vaccine register). It will include more than 22000 children from one province in Cuba. Another province with similar pattern of serotype circulation will be selected as concurrent control [23].

Cost-effectiveness and population impact modeling using economic and mathematical models.

In Step III (post introduction of the new vaccine), the effectiveness, cost-effectiveness and impact on population health will be monitored. Strategies of sentinel surveillance, epidemiological studies and impact evaluation are combined; including economic evaluation. Pharmacovigilance studies will be conducted to monitoring the safety profile, usage and vaccine satisfaction.

\section{C) Analysis and evaluation of scientific evidence}

The evidence contribution to support decision-making regarding the introduction and commercialization will be presented in three dimensions: magnitude of the study problem estimation, demonstration of vaccine functioning and cost-effectiveness evaluation.

The analysis and appraisal of the generated evidence will allow grading evidence for decision-making according to the methodology proposed by the workgroup GRADE [24]. 
Citation: Linares-Pérez N, Toledo-Romaní ME, Mederos DS, Valdés-Balbín Y, García-Rivera D, et al. (2018) Evaluation Strategy to Support the Introduction the New Cuban Conjugated Pneumococcal Vaccine in the National Health System . J Vaccines Vaccin 9: 385. doi: $10.4172 / 2157-7560.1000385$

Page 5 of 8

\section{(III) Vaccine introduction}

The strategy for PCV vaccination in Cuba is proposed taking into account the need to prevent the phenomenon of serotype replacement and the opportunity of reaching high and sustainable coverage in pneumococcal disease target population. Vaccine introduction will be planned by phases as follows:

First phase, it is envisaging to reach children population from 1 to 5 years old achieving high coverage (superior to 95\%) in a short time (vaccination campaign) to impact on serotypes circulation of vaccine and to generate a herd protection in infants. Two doses will be administered to children from 1 to 2 years old and single dose in children from 2 to 5 years Second phase: To introduce in the immunization program, infant vaccination proposing schedules of reduced doses $(2 p+1)$, with previously demonstrated functionality in clinical trials ((RPCEC00000243) of protective efficacy comparing different schedule dose [25].

\section{(IV) Measurement of health impact}

Three dimensions will be included for impact evaluation: 1) impact on the burden disease and colonization (incidence of invasive and non-invasive disease, prevalence of global colonization and by serotypes, proportion of antimicrobial resistance by serotype); 2) changes in epidemiological patterns associated to the introduction and usage of the vaccine (reduction of pneumococcal disease incidence by vaccine serotypes, proportion of serotype replacement, reduction of the hospitalization rate by meningitis and respiratory syndromes associated to pneumococcal infection; and 3) global impact on infantile health (reduction of mortality in infants and under 5 years children, prevalence of malnutrition, rate of global hospitalization and by respiratory infections).

\section{Evaluation strategy operationalization in Cuban context}

The operationalization of the strategy evaluation of PCV7-TT in Cuban context is summarized in (Figure 3).

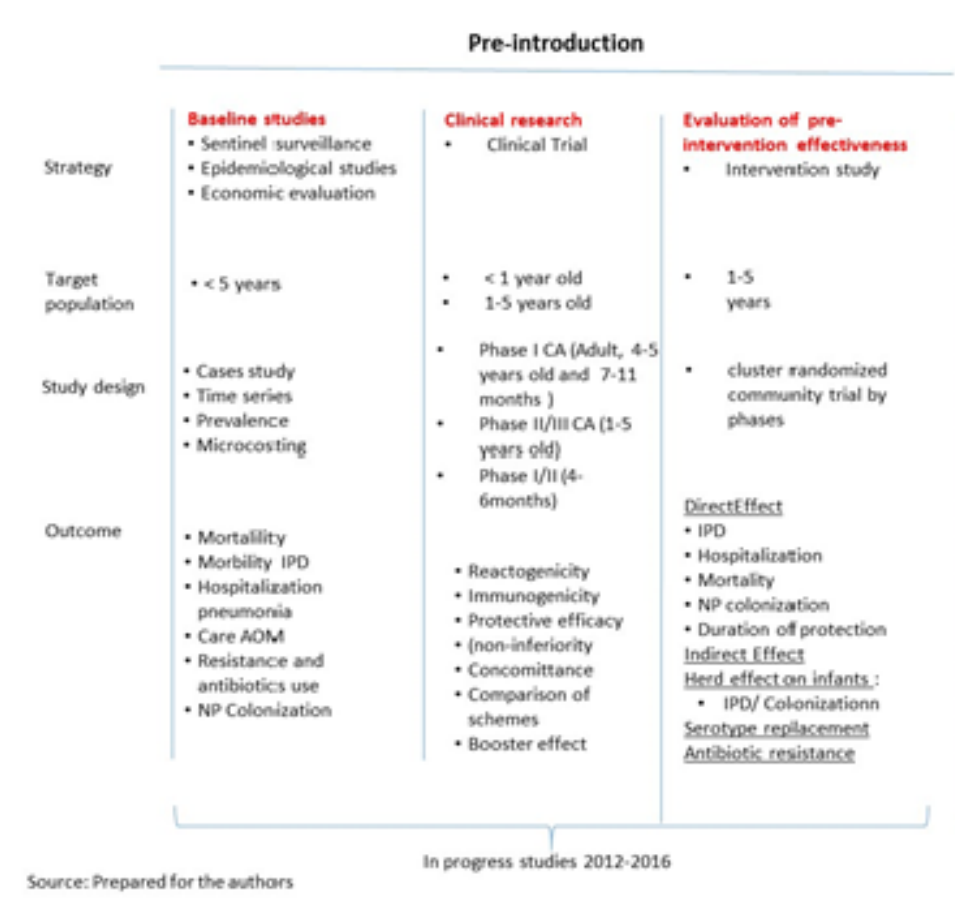

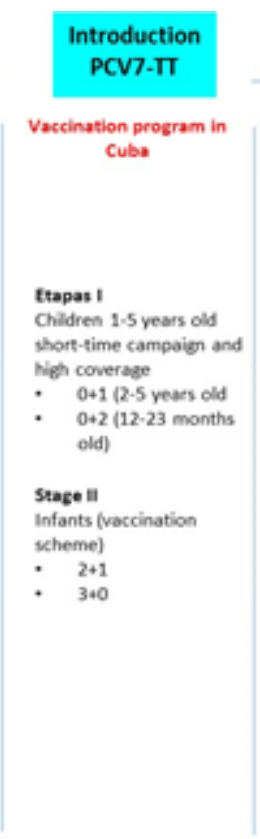

For 2017-2018

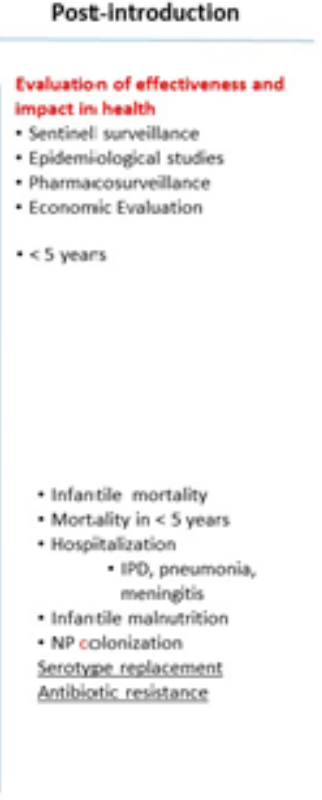

Follow-up for 5-7 years

Figure 3: Operationalization of the evaluation model for the introduction PCV7-TT in the Cuban context

The introduction of the vaccine will be preceded, at least two years, by a baseline data collection, permitting post introduction comparisons [26]. Clinical research by controlled clinical trial will reach different target groups to demonstrate the efficacy of the Cuban vaccine candidate. The pre-registry cluster community trial will permit the effectiveness evaluation in vaccines (direct effect), the herd protection in infants (indirect effect) and the impact at population level, as well as duration of protection. Post registry monitoring and evaluation of vaccinated and unvaccinated children will be carrying out during five years after introducing the vaccine in the national vaccination program to investigate how many IPD or non-IPD cases are caused by vaccine serotypes. 
Citation: Linares-Pérez N, Toledo-Romaní ME, Mederos DS, Valdés-Balbín Y, García-Rivera D, et al. (2018) Evaluation Strategy to Support the Introduction the New Cuban Conjugated Pneumococcal Vaccine in the National Health System . J Vaccines Vaccin 9: 385. doi: $10.4172 / 2157-7560.1000385$

Page 6 of 8

\section{Discussion}

The proposed evaluation frame supports the Cuban strategy of development and evaluation of a new vaccine for its introduction by the health system and its posterior marketing. It will allow generating scientific evidences on safety, efficacy, effectiveness as well as the cost, cost-effectiveness and impact on health of PCV7-TT.

Moreover, it will permit to document the changes in the epidemiological pattern of the pneumococcal disease, the serotype prevalence and post-vaccine introduction microbial resistance.

Novel elements for international literature are the findings on immunogenicity using reduced doses schedule in two target populations [27], and the demonstration of the effectiveness and population impact introducing pneumococcal vaccination with high coverage in a short period of time in children from 1 to 5 years old as target population, to generate herd protection in infants because the impact on pneumococcal circulation.

From methodological viewpoint, the strengths of the strategy are: 1) the integration of different perspectives: clinical \& evaluative research, organization of surveillance and diagnostics services, measurement of effectiveness and impact, 2) integration of effectiveness on disease with hospitalization rates and changes of the carrier status as principal endpoints, which so far were dispersed in literature, 3) the frame to build the body of scientific evidence, supposing the closing of the product complete cycle, 4) foreseen mechanisms of monitoring and evaluation of the rigor of scientific evidence (internal validity) and applicability (external validity), 5) the monitoring of serotypes and microbial resistance by sentinel surveillance, and 6) the measurement of the population effect attributed to pneumococcal vaccination in Cuba at median and long terms.

Weakness are defined as those resulting from routine information reliability of surveillance and statistical systems; which should be minimized with protocoling, monitoring and evaluation in sentinel sites, where the strength of capacities and the technological development have been foreseen. The combination of study designs, information sources, data collection techniques and indicators, will allow controlling inherent limitations to each study design [28]. Adherence to good clinical practices [29,30] will ensure quality of results and the compliance with ethics principles for research in humans.

Considering the challenges in the evaluation process of the new Cuban pneumococcal vaccine this paper was aimed at three main axes: the change of paradigm in the evaluation framework, the strategies design, and the generation process of scientific evidences for decisionmaking.

\section{The change of paradigm in the evaluation frame}

The introduction, adoption, diffusion and marketing of vaccines, as well as other sanitary technology should be guaranteed by the confirmation of safety, efficacy, effectiveness and relation costconsequence. Otherwise, means ethical problems.

Assuming the methodological frame of the so-called "complex" interventions is the first challenge in the evaluation of the new pneumococcal vaccine, because usually vaccine-based interventions are considered "simple" or "uni-component" [31]. This fact is based on the number and variability of the used effectiveness or impact measures (outcomes), the number of target groups enrolled (infants, preschool children, chronic patients, elderly, and the number of institutions of different levels (hospitals, laboratories, primary health care areas, research centers) involved in the evaluation process.

\section{Design of the evaluation strategy}

The evaluation is a bridge between scientific evidence and decisionmakings since it provides information at macro and micro levels [32].

The second challenge in designing the PCV7-TT evaluation strategy is the need of combining different designs to answer different research questions, to clinical evaluation and impact measurement to support decision-making on its introduction, use and marketing.

WHO [6] considers that the introduction of new pneumococcal vaccines is influenced by political and technical criteria. In addition, it suggests that the demonstration of the impact on the pneumococcal disease is important to support political decisions on vaccine introduction and use and to allow the society to consider the benefits and to evaluate the programmatic use

The evaluation strategy designed should answer questions such as: 1) Is the disease intended to be prevented a political and public health priority?, 2) Does the disease have an important magnitude, evaluated in terms of incidence, prevalence, disability, hospitalizations and mortality in the country?, 3) Is the available vaccine safe, efficient?, does it have quality?, 4) Is the proposed vaccine the best intervention for the disease control?, 5) What is the cost-effectiveness relation of the vaccine?, and 6) Which is the impact of the vaccine introduction [33].

The need of defining key processes and main components according to the innovation model proposed by Roger in 1995 was the consulted experts' criteria to ensure the external validity of the evaluation strategies and its applicability to other products and technologies, mainly vaccines [34].

\section{Process of scientific evidence generation}

The need of building a robust body of evidences, complying with the requirements of the international scientific community and of the regulatory institutions is the third challenge for building the evaluation strategies of the Cuban vaccine.

In the specific case of pneumococcal vaccines, the scientific evidence on safety evaluation, immunogenicity, the effect on the carrier status and dose schedules comparisons have been widely supported in literature and it based on hard designs of clinical studies involving large cohorts of vaccines and follow-up of systematic reviews and metanalysis [17-22]. For this reason, the generation of evidences of the new Cuban vaccine should be rigorous enough to ensure international comparisons and it's positioning as product in vaccine markets.

Besides, it should be considered that the registry of new pneumococcal vaccines is well regulated by standards and positioning criteria of international organizations such as the WHO [35] and national regulatory agencies in Cuba [29] and other with similar functions in the United States and Europe.

Controlled and randomized experimental studies, rigorously conducted to ensure internal validity, will provide an evidence level I. Cluster Community trial and analytical observational studies of cohort and case-control generate evidences of levels II-1 and II-2, respectively. All this, together with the evaluation of cost and cost-effectiveness (levels Ia and Ib), have the intention of placing all the information 
Citation: Linares-Pérez N, Toledo-Romaní ME, Mederos DS, Valdés-Balbín Y, García-Rivera D, et al. (2018) Evaluation Strategy to Support the Introduction the New Cuban Conjugated Pneumococcal Vaccine in the National Health System . J Vaccines Vaccin 9: 385. doi: $10.4172 / 2157-7560.1000385$

Page 7 of 8

generated on PCV7TT in a recommendation grade of A [36] for its use and commercialization.

\section{Conclusions}

The evaluation strategy of the new Cuban pneumococcal vaccine would close the complete development cycle of the biotechnology product in Cuba. It is supported on international standards and recommendations for the evaluation of pneumococcal conjugated vaccines and it goes from the context analysis to the measurement of impact on health after introduction. The generation of new scientific evidence is based on the combination of methodological procedures and on rigorous, valid and reliable study designs that can be applied in the evaluation of other products and technologies in different scenarios. The synthesis and appraisal of the evidences on PCV7-TT, will allow decision-makings for its introduction and use by the health system.

The proposed strategy for the implementation of pneumococcal vaccination in Cuba may contribute to the scientific knowledge by answering questions on the importance of the herd effect in infants when children from 1 to 5 years are massively vaccinated; and will give new insights if this strategy could be used in the future to prevent reemergence of new serotypes combined with innovative schedules of reduced doses.

Cuban biotechnology faces new challenges to position its products in the international market. However, it is time to demonstrate that the Cuban vaccine is an alternative for the so-called South countries, as part of the global strategies to reduce preventable diseases using vaccines in the coming years.

\section{Declaration of Interests}

Main authors of this paper: Nivaldo Linares-Pérez, PhD; Daryelis Santana Mederos, BsC; Yury Valdés-Balbín, BsC; Dagmar GarcíaRivera and Vicente Verez-Bencomo, $\mathrm{PhD}$ are employees at the manufacturing vaccine center "Finlay Vaccine Institute". María E. Toledo-Romaní, PhD working in the National Health System neither have contracts nor receive financing from the manufacturing center.

\section{Contributions of Authors}

NLP, MET, DSM, YVB, DGR and VVB contributed to the design of the evaluation strategies described in this paper. NLP and MET writing the text, and the all authors were involved in the discussion, review and approval of the final text version.

\section{Acknowledgments}

The authors wish to thank to all scientists, professionals and specialists, members of the Workgroup for clinical research and impact evaluation of the Cuban pneumococcal vaccine*: Finlay Vaccine Institute: Laura M Rodriguez-Noda, Marisel Martinez, Ivan Cuevas, Mayelín Mirabal, Meiby C. Rodriguez, Alina Alvarez, Beatriz Paredes, Marlene Armesto, Raúl Mujica, Isabel Luis Gonzálvez. Tropical Medicine Institute "Pedro Kourî": Gilda Toraño, Susana Borroto, Misladys Rodriguez, Alicia Reyes. Public Health National School: Anaí García-Fariñas, Ana Maria Gálvez, and Martha Marrero. Clinical sites at Cienfuegos: Maria F Casanova, Dunia Chávez and Alain Reyes and Clinical sites at La Habana: Carlos Dotres and Rinaldo Puga. Sentinel Surveillance Network of Pneumococcal Project: María Elena Mesa,
Niurka Molina Águila, Ernesto Legarreta Peňa, Dania Vega Mendoza, Gladys Abreu, Gladys Fuentes, Miosotis Pérez Orta, Lidia Teresita Ramos, Concepción Infante, María Cristina Reyes López (La Habana), Mercedes Fonseca, Martha Montes de Oca, Antonio Velázquez Águila, Iliana García Rodríguez, Cary Tere Llul Tombo y Juan C. Yanes Macías (Cienfuegos), Neyda González, Nordis Caridad Donatién Rojas, Lissett Batista Caluff, Nivia Cobas Limonta, Moraima, Silvia Justiz Hernández, Josefina Herrera López, Malfran García, Luis Enrique Rondón Rondón, Bertha Isabel Rondón Peña, Caridad Tamayo Reus, Magdevis Pajaro Medina, Daisy Díaz Teran, Mariela Cuza Ferrer, María Maren González, Samira Maceira Soto, Itciar Áreas y José R. Guillén (Santiago de Cuba).

Also the authors wish to thank the institutions involved in the Project for the new Cuban pneumococcal vaccine: "Finlay Vaccine Institute" for the role of the funding source in this work. The National Reference Laboratory for pneumococcus of the Tropical Medicine "Pedro Kouri"; the Health Economics Department at the National School of Public Health in Cuba, and the National Vaccination Program from the Ministry of Public Health.

\section{References}

1. Ministerio de Salud Pública (2013) Consenso nacional para el diagnóstico y tratamiento de la neumonía adquirida en la comunidad en pediatría. Ministerio de Salud Pública. La Habana, Cuba.

2. Gladys AS, Aurelia PPB, Gladys FF, Reina PL, Miosotis P (2017) Hospitalizaciones por neumonía adquirida en la comunidad. Rev Cubana Pediatr 89: 1.

3. http://www.paho.org/hq/index.php? option=com_docman\&task=doc_download\&gid=22372\&Itemid=270

4. Toraño-Peraza G, Pías-Solis L, Abreu-Capote M, Rodríguez-Ortega M, Dickinson-Meneses F, et al. (2014) Serotipos y resistencia antimicrobiana de aislamientos meníngeos de Streptococcus pneumoniae. Cuba, 2007-2012. Vaccimonitor 23: 117-123.

5. Dickinson MF, Rodríguez OM, Toraño PG (2015) Pneumococcal meningitis in Cuban children and adolescents: A fifteen years follow up. Pediatr Res Inter J 2015: 11.

6. WHO (2012) Pneumococcal vaccines WHO position paper-2012recommendations. Vaccine 30: 4717-4718.

7. Organización Panamericana de la Salud (2011) Programa Ampliado de Inmunizaciones. Precio de las vacunas para el 2011. Enmienda III, 27-6-2011. OPS Washington DC.

8. Zamorano J (2010) Nuevas vacunas antineumocócicas conjugadas: recorriendo su éxito. Medwave 10: e4375.

9. Evelyn B, Laurence G, Harish N, Moe HK (2017) Serotype distribution of Streptococcus pneumoniae causing invasive disease in children in the post-PCV era: A systematic review and meta-analysis. PLoS One 12: e0177113

10. Johnson HL, Deloria-Knoll M, Levine OS, Stoszek SK, Freimanis HL, et al. (2010) Systematic evaluation of serotypes causing invasive pneumococcal disease among children under five: the pneumococcal global serotype project. PLoS Med 7: 1251.

11. The International Vaccine Access Center (2017) Summary of the Pneumococcal Conjugate Vaccine (PCV) Product Assessment.

12. http://www.cecmed.cu/sites/default/files/adjuntos/Reglamentacion/ res.no_.219.regulacion.m_82-15.pdf. July 22th, 2016.

13. Moore GF, Audrey S, Barker M, Bond L, Bonell C, et al. (2015) Process evaluation of complex interventions: Medical Research Council guidance. Bmj 350: h1258.

14. Whitney CG, Goldblatt D, O'Brien KL (2014) Dosing schedules for pneumococcal conjugate vaccine: considerations for policy makers. Pediatr Infect Dis J 33: S172-S181. 
Citation: Linares-Pérez N, Toledo-Romaní ME, Mederos DS, Valdés-Balbín Y, García-Rivera D, et al. (2018) Evaluation Strategy to Support the Introduction the New Cuban Conjugated Pneumococcal Vaccine in the National Health System . J Vaccines Vaccin 9: 385. doi: $10.4172 / 2157-7560.1000385$

Page 8 of 8

15. Andrus JK, Toscano CM, Lewis M, Oliveiria L, Ropero AM, et al. (2007) A model for enhancing evidence-based capacity to make informed policy decisions on the introduction of new vaccines in the Americas: PAHO's ProVac initiative. Public Health Rep 122: 811-816.

16. Atkins D, Eccles M, Flottorp S, Guyatt GH, Henry D, et al. (2004) Systems for grading the quality of evidence and the strength of recommendations I: critical appraisal of existing approaches The GRADE Working Group. BMC health serv Res 4: 38.

17. Thompson A, Gurtman A, Patterson S, Juergens C, Laudat F, et al. (2013) Safety of 13-valent pneumococcal conjugate vaccine in infants and children: meta-analysis of 13 clinical trials in 9 countries. Vaccine 31: 5289-5295.

18. Knoll MD, Park DE, Johnson TS, Chandir S, Nonyane BAS, et al. (2014) Systematic review of the effect of pneumococcal conjugate vaccine dosing schedules on immunogenicity. Pediatr Infect Dis J 33: S119-S129.

19. Fleming-Dutra KE, Conklin L, Loo JD, Knoll MD, Park DE, et al. (2014) Systematic review of the effect of pneumococcal conjugate vaccine dosing schedules on vaccine-type nasopharyngeal carriage. Pediatr Infect Dis J 33: S152-160.

20. Conklin L, Loo JD, Kirk J, Fleming-Dutra KE, Knoll MD, et al. (2014) Systematic review of the effect of pneumococcal conjugate vaccine dosing schedules on vaccine-type invasive pneumococcal disease among young children. Pediatr Infect Dis J 33: S109-118.

21. Park DE, Johnson TS, Nonyane BAS, Chandir S, Conklin L, et al. (2014) The differential impact of coadministered vaccines, geographic region, vaccine product and other covariates on pneumococcal conjugate vaccine immunogenicity. Pediatr Infect Dis J 33: S130-139.

22. Surasak S, Ajaree R, David BCW (2016) Cost Effectiveness of Pneumococcal Vaccination in Children in Low- and Middle-Income Countries: A Systematic Review. PharmacoEconomics 34: 1211-1225.

23. http://rpcec.sld.cu/ensayos/RPCEC00000255-Sp.

24. Sanabria AJ, Rigau D, Rotaeche R, Selva A, Marzo-Castillejo M, et al. (2015) Sistema GRADE: metodología para la realización de recomendaciones para la práctica clínica. Atención Primaria 47: 48-55.
25. http://rpcec.sld.cu/ensayos/RPCEC00000243-Sp

26. Linares-Pérez N, Toledo-Romaní María E (2017) La vigilancia y la evaluación de impacto como estrategias de salud pública: Aportes para la introducción de la nueva vacuna cubana contra Streptococcus pneumoniae. Send to Vacunas 89: 1.

27. O'Brien K (2017) When less is more: how many doses of PCV are enough? The Lancet Infect Dis 18: 127-128.

28. Szklo M, Nieto FJ (2003) Epidemiología intermedia: conceptos y aplicaciones: Ediciones Díaz de Santos.

29. Quinche F (2006) WHO, Handbook for good clinical research Practice (GCP) 2005Guidance for Implementation. Éthique \& Santé 3: 177-178.

30. Organización Panamericana de la Salud (2005) Editor Buenas prácticas clínicas: documento de las Américas. IV Conferencia Panamericana para la Armonización de la Reglamentación Farmacéutica.

31. Craig P, Dieppe P, Macintyre S, Michie S, Nazareth I, et al. (2008) Developing and evaluating complex interventions: the new Medical Research Council guidance. BMJ 337: a1655.

32. Campbell NC, Murray E, Darbyshire J, Emery J, Farmer A, et al. (2007) Designing and evaluating complex interventions to improve health care. BMJ 334: 455-459.

33. Clark A, Jauregui B, Griffiths U, Janusz CB, Bolanos-Sierra B, et al. (2013) TRIVAC decision-support model for evaluating the cost-effectiveness of Haemophilus influenzae type b, pneumococcal and rotavirus vaccination. Vaccine 31: C19-29.

34. Rogers EM (2002) Diffusion of preventive innovations. Addict behav 27: 989-993.

35. Progress in introduction of pneumococcal conjugate vaccine worldwide, 2000-2012 (2013) Releve epidemiologique hebdomadaire/Section d'hygiene du Secretariat de la Societe des Nations=Weekly epidemiological record/Health Section of the Secretariat of the League of Nations 88: 173-180.

36. Castillejo M, Zulaica C (2007) Calidad de la evidencia y grado de recomendación. Guías clínicas 7: 12-31. 